\title{
Utilization of an ICF-based assessment from occupational therapists' perspectives
}

\author{
Anette Kjellberg, Vedrana Bolic and Lena Haglund
}

\section{Linköping University Post Print}

N.B.: When citing this work, cite the original article.

Original Publication:

Anette Kjellberg, Vedrana Bolic and Lena Haglund, Utilization of an ICF-based assessment from occupational therapists' perspectives, 2012, Scandinavian Journal of Occupational Therapy, (19), 3, 274-281.

http://dx.doi.org/10.3109/11038128.2011.560962

Copyright: Informa Healthcare

http://informahealthcare.com/

Postprint available at: Linköping University Electronic Press

http://urn.kb.se/resolve?urn=urn:nbn:se:liu:diva-73093 
Utilization of an ICF-based assessment from occupational therapists' perspectives

Authors: $\quad$ Anette Kjellberg MScOT, PhD

Vedrana Bolic MScOT

Lena Haglund MScOT, PhD, Ass. Prof.

Department of Social and Welfare Studies, Faculty of Health Sciences, Linköping University, Sweden

Address for correspondence:

Anette Kjellberg

Linköping University

Faculty of Health Sciences

Department of Social and Welfare Studies

SE-601 74 Norrköping

Sweden

Telephone: + 4611363279

Telefax: + 4611125448

E-mail: anette.kjellberg@liu.se 


\section{ABSTRACT}

The International Classification of Functioning, Disability and Health (ICF) is intended to provide a framework for practitioners. A client-centred ICF-based assessment (ICF-A) was developed to be used by occupational therapists in problem identification. The aim was to evaluate the ICF-based assessment (ICF-A) focusing on the examination of its utility on the basis of occupational therapists' perspectives regarding clinical relevance and potential for implementation. Eleven occupational therapists, most of whom worked in hospitals, performed in total 99 ICF-A based assessments and completed three self-reported questionnaires related to the utility of the ICF-A, resulting in a total of 121 questionnaires. Data were analysed using descriptive statistics and directed content analysis. The results from this initial testing of ICF-A showed that its clinical relevance was considered low since ICF-A included too many categories. In addition, the time needed to perform the assessments decreased during the ten assessment occasions. Furthermore, concerning its implementation potential, the client-centred approach in the ICF-A was rated as weak. The target group did not benefit from using ICF-A in a hospital context. Hence, an investigation of its utility among occupational therapists in community and primary care will be the next step in the development of the ICF-A.

Keywords: assessment, client-centred, International Classification of Functioning, Disability and Health (ICF), occupational therapy 


\section{INTRODUCTION}

One of the applications of the International Classification of Functioning, Disability and Health (ICF) is as a tool for clinicians (1). However the ICF cannot replace occupational therapy models but rather complements current versions of them $(2,3,4)$. Since the ICF is a worldwide recognized health and health-related classification and aims to have an impact on health and social care systems and also to facilitate communication between professions, people with disabilities, organisations and countries it is crucial that different health professions are involved in the development and clinical application of the ICF $(2,5,6,7)$. The current study can be considered as an attempt to contribute to this development. For the present study, an ICF-based assessment (ICF-A) was developed by Haglund \& Kjellberg (8) including all chapters and categories in the ICF component's activity and participation and environmental factors. ICF-A is intended to enable problem identification regarding the complex interaction between the individual and the environment and is based on operational definitions in ICF (1).

\section{ICF-A}

\section{Theoretical background and purpose of the ICF-A}

ICF (1) classifies functioning, disability and health from body, individual and societal perspectives on the basis of an integrated biopsychosocial perspective on health. The ICF contains the components of body functions (physiological and psychological functions of body systems) and body structures (anatomical parts of the body), activities (actions and tasks executed by the individual) and participation (involvement in a life situation). In addition, environmental factors that impact on all aspects of functioning are represented in the ICF. In the ICF, each component is divided into chapters and categories, which make up the unit of 
classification. Within each chapter there are two-, three-, or four level categories. (1). The ICF-A covers all chapters and categories on level two in the ICF component's activity and participation and environmental factors. The purpose of ICF-A is to be a client-centred assessment that gathers data concerning problem identification in life areas in which the individual has resources and/or problems related to "activity and participation" and facilitators and barriers in the environment for "environmental factors". It is intended to be used in various clinical settings in the initial assessment when meeting a new client, namely, regarding problem identification. The ICF-A is not diagnosis-specific, but its use is limited to adults, who are defined as people aged 18 or older. When initially using the ICF-A, it is necessary to use the ICF (1) in order to learn and understand the definition of each component and category.

\section{Development of the ICF-A}

The development of ICF-A was conducted by a step-by step process of four phases: the planning, construction, evaluation and validation phases as described by Benson \& Clark (9). The planning phase started with the formulation of the purpose of the assessment. Furthermore, the target group was defined, that is, adults with various diagnoses. After that, a literature review in the area of available application instruments based on the ICF was carried out (9). The result of this review motivated the development of a new assessment based on the ICF as there is, to the best of our knowledge, no available assessment that meets our demands for addressing all environmental chapters and categories in combination with all activity and participation chapters and categories as described in the ICF (1).

During the construction phase of the ICF-A, the client-centered approach was realized by including all chapters and categories on level two in the ICF component's activity 
and participation and environmental factors. Furthermore, the ICF-A gives the opportunity for the occupational therapist to involve the client in choosing and deciding assessment procedure, occupational performance area and activity/activities. This opportunity to include the client's perspectives and values enables client-centeredness and is crucial in the occupational therapy process (10). Flexibility is essential when using assessments in clinical practice, and this is related to allowing the clinician the opportunity to modify and adapt the assessment occasion to meet the purpose of the assessment and the client's needs (11). The component "environmental factors" covers the physical, social and attitudinal environment. In the score sheet for the component "environmental factors" each category is rated as a facilitator or barrier for the occupational performance of the person. The score sheet for "activity and participation" is used to describe in which life areas the individual has resources and/or problems, that is, problem identification. For rating on the score sheet for "activity and participation", a 5-point rating scale (no problem, mild to moderate problem, severe problem, very severe problem and not applicable) is used. The first qualifier is used to describe the extent of the problem (1). It is important to take into consideration and rate all categories on the two score sheets to ensure client-centeredness (10). Different assessment procedures can be selected including: self-assessment, interview, observation, a combination of interviewing and observation, interview with relatives, staff or other people who know the client, and use of registry data. Furthermore, the area of occupational performance and activity/activities (activities of daily living, work, education and leisure) must be specified on both score sheets (see Appendix 1).

The third phase is the evaluation phase, which includes evidence of qualities and several different forms of validity and reliability. The pilot version of the ICF-A was reviewed individually by a panel of experts in assessment development and ICF regarding content and the design of the assessment. The experts were asked to evaluate whether the 
ICF-A actually measures what it is claimed to measure (12). The result of this face validity evaluation ended in minor adjustments to the ICF-A. The next step was to evaluate the utility of the ICF-A.

The utility refers to the overall value of the assessment to the user $(11,13,14,15)$. When examining the utility of an innovation, in this case an assessment in a practical setting, Polit and Beck $(14,15)$ recommend a number of issues that must be taken into consideration, mainly the clinical relevance, scientific merit and the implementation potential of the assessment. The clinical relevance is described by the likelihood of the assessment being significant when making appropriate observations, supporting practitioners in decisionmaking and improving inter-professional communication. The scientific merit as described in the utilization process refers to the body of research available that addresses the same issue. Regarding the implementation potential, several different aspects should be considered, in particular, the transferability, the feasibility and the cost/benefit ratio of the innovation, in this case, the ICF-A. The transferability refers to the value of implementing the assessment by addressing aspects of how well the assessment will fit in the new setting. The main issue regarding the transfer of an assessment is the congruence between the assessment and clinical practice in terms of the type of clients it serves, the financial and administrative structure, and the time needed to implement the assessment. The feasibility highlights various practical aspects that may affect the implementation, such as the availability of resources, the organization and the ability to perform clinical evaluation. The cost/benefit ratio refers to the costs and benefits of implementing the assessment, and is not included in the present study. Accordingly, this study focuses on utility.

\section{AIM}


The current study is an evaluation of the ICF-based assessment (ICF-A) focusing on examination of its utility on the basis of occupational therapists' perspectives regarding clinical relevance and potential for implementation.

\section{MATERIAL AND METHODS}

\section{Participant selection, procedure and administration of the ICF-A}

The participants comprised of 11 occupational therapists, of which eight were working in hospital-based care (73\%) and three in an outpatient psychiatric unit (27\%). The participants were selected in association with the heads of a nearby healthcare-related administrative region. Inclusion criteria were occupational therapists working in hospital-based occupational therapy care and in an outpatient psychiatric unit with adult clients and attendance at a threehour-long introduction session including a lecture on the International Classification of Functioning, Disability and Health (ICF) (1) and instructions on how to use the ICF-A (8). Twenty-four occupational therapists attended the introduction session and 18 occupational therapists consented to participate in the study. Seven of these 18 occupational therapists were later excluded from the study since they themselves chose to withdraw from it. The participants were asked to use the ICF-A when there was a need to assess activity and participation as well as environmental factors when meeting clients in their regular work. During a period of three months, the occupational therapists were asked to use the ICF-A when assessing ten different clients. Eight occupational therapists performed ten assessments each, and three participants performed eight, seven or four assessments. In total, 99 assessments were performed by the 11 occupational therapists. This study was developed in accordance with the ethical guidelines of the Council for Research in Humanities and Social Sciences (16). 


\section{Self-reported questionnaires}

Three self-reported questionnaires were developed to evaluate the utility of the ICF-A, following guidelines from Polit and Beck $(14,15)$. The participants $(n=11)$ completed the first questionnaire at the end of the three-hour introduction session, the second questionnaire after each performed client assessment $(n=99)$ and the last questionnaire when the participants $(n=11)$ had performed all their assessments. In total, 121 questionnaires were completed. The three questionnaires focused on clinical relevance and implementation potential, that is, transferability and feasibility. In total the three self-reported questionnaires included 34 questions (four of these questions focused on demographic data, 12 focused on clinical relevance, nine on transferability and nine on feasibility). Questions focusing on clinical relevance were for example: Are you in need of an additional assessment in the area of activity and participation and environment? Regardless of your previous knowledge about the client, does the ICF-A provide sufficient knowledge about the client? Examples of questions focusing on transferability were: How long did it take for you to perform the assessment? What was the reason for the choice of data collection method and the area of occupational performance and activity/activities? How did you benefit from the opportunity to choose a data collection method and area of occupational performance and activity/activities? Part of the questionnaires focused on feasibility for example: Describe your previous knowledge of the ICF. Describe your previous use of the ICF. The questions were constructed as both openand closed-ended questions, using both nominal and ordinal scales. 


\section{Data analysis}

Descriptive statistics were used to describe the following: demographic data of the occupational therapist and the assessed clients, the frequency of categories in each component, time required for administration of the assessment, the occupational therapists perception of the ability to perform the assessments and choice of and benefit from choosing occupational performance area and assessment procedure. The data were analysed using SPSS software for Windows (17). To obtain an overall view of data the open-ended questions in the three questionnaires were read several times before the analysis started. The data were analysed using directed content analysis as described by Hsieh \& Shannon (18) implying that the coding is based on predetermined categories. According to Polit \& Beck $(14,15)$ utilization criteria are clinical relevance, transferability and feasibility hence these became the predetermined categories. Each answer in each questionnaire was searched line by line and coded. The coded data was examined and compared with the theoretical descriptions of the predetermined categories $(14,15)$. The second author conducted the coding while the first and third authors served as peer-reviewers. Strategies for trustworthiness were considered. To increase the dependability of the study the analysis and coding of data into the categories were continuously discussed during the process and enabled a consensus to be reached among the authors (19).

\section{RESULTS}

\section{Characteristics of the occupational therapists and clients assessed}

All of the participants were female $(n=11)$ and included individuals with a wide range of working years (range 1-28 years). All participants had the qualification of Bachelor of 
Science in Occupational Therapy. In addition, one had a Master's degree. Five participants had taken one or more postgraduate courses related to the workplace. Six of the occupational therapists performed assessments on a daily basis, and five participants did so several times during the week by using formal assessment. All but two occupational therapists stated that they also used informal assessments. The occupational therapists' responses showed that formal assessment instruments such as the ADL taxonomy (20) and the Worker Role Interview (WRI) were used (21). Table I shows the characteristics of the clients that were assessed. (Insert Table I about here.)

\section{Clinical relevance}

Concerning clinical relevance, all of the occupational therapists agreed that there was a need for further assessment in the areas of environment, activity and participation. Five of the participants stated that using the ICF-A gave them more extensive knowledge about the factors that facilitate or hinder activity. Four of the eleven occupational therapists stated that the ICF-A consisted of a wide range of unique categories that are of relevance to occupational therapists in a clinical setting. However, all except two of the occupational therapists stated that they would not use the ICF-A in the future and that the assessment did not give them sufficient knowledge about the client. Six of the occupational therapists stated that the ICF-A was too broad and that many categories were not relevant in specific assessment situations. The result furthermore indicated that the ICF-A gives knowledge about the client that is too superficial. One occupational therapist stated that the ICF-A "was too rough in some parts; it appears that the problem exists in a category but specifics are not given, for example, dressing involves many specific activities". All except one stated that the ICF-A did not affect their communication with other team members, the client and his/her relatives. 
The most clinically relevant and frequently used category in the score sheet for “environmental factors" was Chapter Three on support and relationships. The most frequently used category in the score sheet for "activity and participation" were Chapter One on learning and applying knowledge and Chapter Four on mobility (Table II). Recommendations for changes to increase the clinical relevance of the ICF-A were to reduce the number of categories. (Insert Table II about here)

\section{Implementation potential}

\section{Transferability}

The time needed to perform the ratings on the two score sheets decreased during the ten assessment occasions (Table III). On 57\% of the assessment occasions, the time needed to complete the score sheets for "environmental factors" and "activity and participation" was considered as reasonable. (Insert Table III about here.)

The reason for the choice of area of occupational performance and activity/activities was based on limitations in the clients' occupational performance on $42 \%$ of the assessment occasions. In 33\% of the assessment occasions the client selected the area of occupational performance and activity/activities. The occupational therapists' work procedures and their choice of area assessed affected the selection on $17 \%$ of the assessment occasions. The opportunity to choose an area of occupational performance and activity/activities for assessment facilitated their ability to vary their way of working on $43 \%$ of the assessment occasions. This could be exemplified by what one occupational therapist stated, namely, that it increased the utility of the ICF-based assessment in clinical practice by "enabling it to be used on multiple clients". On $28 \%$ of the assessment occasions, the opportunity to choose enabled them to ensure that the activities being assessed were relevant 
and meaningful to the client. On $13 \%$ of the assessment occasions, the participants answered that they did not benefit from the opportunity to choose.

The assessment procedure used for ratings of the categories on the score sheets consisted of observation (59\%), a combination of observation/interview (31\%) and interview (10\%). On $27 \%$ of the assessment occasions, the reason for the choice of assessment procedure was external conditions, such as location, and the context in which the assessment would be used. On $25 \%$ of the assessment occasions, the choice was based on what the occupational therapist planned to assess. One occupational therapist stated: "I planned to make an assessment in the morning so it was natural to observe how the person was doing to assess whether there were any difficulties". On $22 \%$ of the assessment occasions, the participants stated that their choice of assessment procedure was based on the need to obtain an integrated view about the clients' situation. The opportunity to choose the assessment procedure enabled the occupational therapist to ensure that decision-making was relevant to the client's unique circumstances on $59 \%$ of the assessment occasions. On $16 \%$ of the assessment occasions, the answers indicated that the participant did not benefit from the opportunity to choose assessment procedures. On $15 \%$ of the assessment occasions, answers showed that the opportunity to choose the assessment procedure enabled them to obtain a comprehensive understanding of the client's life situation.

\section{Feasibility}

The occupational therapists' perceptions of their ability to perform client assessment with the ICF-A changed in a positive direction across the ten assessment occasions. Table IV shows the occupational therapists' perceptions of their ability to perform client assessment (Insert Table IV about here). Six of the occupational therapists reported that their level of knowledge 
of the ICF was insufficient to use the ICF-A in practice owing to lack of time and experience. The ICF (1) was useful when conducting the actual client ratings on $75 \%$ of the assessment occasions. One therapist stated that she used the ICF (1) "to check the meaning of each category". All of the participants had heard of the ICF, while eight participants had never used it before and two had used the ICF during their Bachelor studies.

\section{DISCUSSION}

The study was an evaluation of the ICF-based assessment (ICF-A) focusing on examination of its utility on the basis of occupational therapists' perspectives regarding clinical relevance and potential for implementation. The results of this study highlight the fact that the ICF-A is too broad and include too many categories. Furthermore, the participants suggested the need to reduce the number of categories to increase the utilization of the ICF-A. Another way to facilitate the use of the ICF in clinical practice is the development of core sets. Core set is a standard selection of ICF components, domains and categories designed to cover the most common aspects of functioning and disability from a particular diagnosis $(22,23)$.

Nevertheless the development of a core set has been questioned for the tendency to focus on domains within body function and structure, and activity and participation $(24,25)$. For example, in the core set for stroke, only $25 \%$ of concepts used are environmental factors. In addition, further studies have emphasized the need to consider all ICF components $(26,27)$. The ICF-A is different when comparing with core sets since all chapters and categories on level two are included in the ICF-A and that it is not developed for specific diagnoses which means that no categories have been selected in relation to a specific diagnosis. Each occupational therapist has responsibility to use the client-centred approach and involve the client in choosing what is the most meaningful and relevant from the client's perspective 
since this is the point of departure in the process of identify goals and implement occupational therapy $(10,28)$. There are limitations with the ICF-A such as it does not cover the components of body functions and body structures. In addition the ICF-A is limited to adults above 18 years. A systematic literature review on ICF (29) and its utilization shows that there are a total of $45 \%$ of the papers focusing on ICF-based tools. The growing trend of the development of ICF-based tools during year 2001-2009 can be interpreted as that the ICF needs to be tailored to different health professionals to be used in a variety of clinical practice. The ICF-A can be regarded as such an example and be considered as a tailor-made assessment based on the ICF for occupational therapists $(2,7)$.

The low level of clinical relevance that the occupational therapists gave the ICFA, when they answered that they will not use the assessment in future, is a critical result. However, this was a small study group and further studies with occupational therapists in different settings such as community care and primary care are needed. It can be asked whether ICF-A is more applicable and useful in these settings. This issue also requires future examination. In addition, to implement an innovation takes time; therefore, it is reasonable that influencing the professional language of occupational therapists is a too high aspiration since the study was only conducted over a period of three months. However, the large number of categories on the second level was considered as a disadvantage for the occupational therapists in this study and resulted in low implementation potential for the ICF-A. In the present study, no selection was carried out regarding categories in the component's activity and participation and environmental factors. This offers a client-centred approach since it allows the clients to make individual choices concerning which categories are most meaningful to focus on in the assessment

Regarding the implementation potential the results showed that only one-third of the participants used the opportunity to choose an area of occupational performance on the 
basis of the client's experience when applying the ICF-A indicates that this must be monitored in the continued testing of the ICF-A. One question that needs to be posed is: Does the manual explain the idea that the ICF-A is a client-centred assessment sufficiently clearly? If there are deficiencies in the manual, these must be resolved, since occupational therapists have to act in accordance with existing laws in Sweden $(30,31,32)$ and the Swedish Code of Ethics $(33)$. The laws $(30,31,32)$ ensure that the services provided are based on integrity and respect for the individual's right to self-determination which implies that the client actively participates in the occupational therapy process. Hemmingson \& Jonsson (7) criticize the ICF concept of participation for lacking focus on the subjective experience of meaning. The subjective experience of participation affects the individual's experience of autonomy and self-determination which are important aspects to experience participation in daily activities. Furthermore, Nordenfelt (34) questioned the fact that, with the support of the ICF one can describe participation only on the basis of the individual actual performance of an activity, resulting in the individual's subjective experience of performing an activity not being included. From an occupational therapy perspective, there is a need to consider the individuals' subjective experience of meaning when talking about participation (7).

Furthermore, concerning the implementation potential, the results of this study revealed that all of the occupational therapists agreed in the initial stage that there was a need for assessments in the areas of activity and participation, as well as environment, since these areas have not been extensively developed in occupational therapy. The result indicated that the time needed to perform the ratings on the two score sheets decreased notably from the first to the tenth assessment occasion. In addition, the time needed to complete the score sheets for "environmental factors" and "activity and participation" was considered as reasonable on 57\% of the assessment occasions. Polit \& Beck $(14,15)$ emphasize that the time needed to implement the assessment in clinical practice is crucial when considering utility. The decrease 
in time required to assess and document lends preliminary support to the transferability of the ICF-A.

\section{Methodological considerations}

Various methodological aspects of this study need to be taken into consideration. The small number of participants $(\mathrm{n}=11)$ is a limitation. Although the study is based on 99 assessments and 121 questionnaires, in further research, there is a need to include a larger number of participants from different settings such as community care and primary care . The collection of data was undertaken with the ICF- A (8) and questionnaires developed by the authors. The fact that the ICF-A was developed by a process of expert review supports its face validity. The questionnaires were developed by following theoretical guidelines from Polit and Beck $(14,15)$ regarding utilization, which also supports its face validity. Nevertheless, several studies need to be performed concerning utility, reliability and validity. The authors have applied available references and consider them to be sufficient to operationalize utility. It is likely that this knowledge will grow in occupational therapy in the future.

\section{Conclusion}

The evaluation phase is referred to as a continual process by Benson and Clark (9) and the development of the ICF-A is just in the initial part of this phase. The current study showed low utility in the practical application of the ICF-A and that the manual needs to be scrutinized by the authors and clarifications concerning the intentions of the client-centred approach must be improved. Further research will be needed to address the weaknesses that were identified in this study. Coming studies will focus on examining the utility of the ICF-A 
in a larger population based on occupational therapists in different settings such as

community care and primary care and extend over a longer period than three months. In

addition, further studies should also focus on its validity and reliability.

\section{REFERENCES}

1. World Health Organization. International classification of Functioning, Disability and Health. Geneva: World Health Organization; 2001.

2. Haglund L, Henriksson C. Concepts in occupational therapy in relation to the ICF. Occup Ther Int. 2003;10:253-68.

3. Haglund L. The ICF vs. occupational therapy instruments - similarities and differences from a mental health perspective. WFOT Bull. 2008;57:5-10.

4. Stamm T, Cieza A, Machold K, Smolen J, Stucki G. Exploration of the link between conceptual occupational therapy models and the International Classification of Functioning, Disability and Health. Aust Occup Ther J. 2006;53:9-17.

5. Stucki G. International Classification of Functioning, Disability and Health (ICF): A promising framework and classification from rehabilitation medicine. Am J Phys Med Rehabil 2005;84:733-40.

6. Üstün B, Chatterji S, Kostanjsek N. Comments from WHO for the Journal of Rehabilitation Medicine Special Supplement on the ICF Core Sets. J Rehabil Med 2004; 37(suppl.44):7-8.

7. Hemmingsson $\mathrm{H}$, Jonsson $\mathrm{H}$. An occupational perspective on the concept of participation in the International Classification of Function, Disability and Health - some critical remarks. Am J Occup Ther 2005;59:569-76.

8. Haglund L, Kjellberg A. Bedömning av komponenterna Aktivitet och delaktighet samt Omgivningsfaktorer i Klassifikation av funktionstillstånd, funktionshinder och hälsa (ICF) för vuxna personer, version 1. In Swedish. Linköpings universitet: Institutionen för Samhälls- och Välfärdsstudier; 2008.

9. Benson J, Clark FA. Guide for instrument development and validation. Am J Occup Ther 1982;36:789-00.

10. Kielhofner G. Model of Human occupation. Theory and Application. $4^{\text {th }}$ ed. Baltimore: Lippincott Williams \& Wilkins; 2008.

11. Innes E, Straker L. Attitudes of excellence in work-related assessments. Work. 2003;2:63-76.

12. Bowling A. Measuring Disease: A Review of Disease-Specific Quality of Life Measurement Scales. Buckingham: Open University Press; 2001.

13. Kielhofner G. Methods of inquiry for enhancing practice. Philadelphia: F.A. Davis Co; 2006.

14. Polit DF, Beck CT. Nursing research: Principles and Methods. $7^{\text {th }}$ ed. Philadelphia: Lippincott; 2004.

15. Polit DF, Beck CT. Nursing Research: Generating and assessing evidence for nursing practice. $8^{\text {th }}$ ed. Philadelphia: Lippincott Williams \& Wilkins; 2008.

16. Vetenskapsrådet. Forskningsetiska principer i humanistisk-samhällsvetenskaplig forskning (Research ethical principles in humanistic and social science). In Swedish. Available at http://www.codex.vr.se/texts/HSFR.pdf. (Accessed 16 November 2008). Available at: http://www.vr.se/download/18.7f7bb63a11eb5b697f3800012802/forskningsetiska_principer_t f_2002.pdf

17. SPSS software for Windows. Version 16. SPSS Inc. Chicago: IL; 2008.

18. Hsieh HF, Shannon, SE. Three Approaches to Qualitative Content Analysis. Qual Health Res. 2005; 15:1277-88.

19. Krefting L. Rigor in qualitative research. The assessment of trustworthiness. Am J Occup Ther. 1991;45:214-22. 
20. Törnquist K, Sonn U. ADL Taxonomi. Bedömning av aktivitetsförmåga. (The ADL taxonomy - evaluation of ADL ability). In Swedish. Nacka: Förbundet Sveriges Arbetsterapeuter; 2001.

21. Ekbladh E, Haglund L. WRI-S. Version 2. In Swedish. Linkoping: Faculty of Health Sciences, Department of Neuroscience and Locomotion; 2000.

22. Maini M, Nocentin U, Prevedini A, Giardini A, Musculo E. An Italian experience in the ICF implementation in rehabilitation: Preliminary theoretical and practical considerations. Disabil Rehabil. 2008;30:1146-52.

23. Mcintyre A, Tempest S. Two steps forward, one step back? A commentary on the diseasespecific core sets of the International Classification of Functioning, Disability and Health (ICF). Disabil Rehabil. 2007;29:1475-79.

24. Stucki G, Cieza A, Ewert T, Kostanjsek N, Chatterji S, Ustün B. Application of the International Classification of Functioning, Disability and Health (ICF) in clinical practice. Disabil Rehabil. 2002;24:281-82.

25. Geyh S, Cieza A, Schouten J, Dickson H, Dommelt P, Omar Z, et al. ICF Core Sets for Stroke. J Rehabil Med 2004;44:135-41.

26. Kirchberger I, Glaessel A, Stucki S, Cieza A. Validation of the Comprehensive International Classification of Functioning, Disability and Health Core Set for Rheumatoid Arthritis: The Perspective of Physical Therapists. Phys Ther. 2007;87:368-84.

27. Kirchberger I, Stamm T, Cieza A, Stucki G. Does the Comprehensive ICF Core Set for Rheumatoid Arthritis capture occupational therapy practice? A content-validity study. Can J Occup Ther 2007;74(suppl.1- 2):267-80.

28. Townsend E. Enabling occupation: An occupational therapy perspective. Revised ed. Ottawa: Canadian Association of Occupational Therapists; 2007.

29. Cerniauskaite M, Quintas R, Boldt C, Raggi A, Cieza A, Bickenbach JE et. Systematic literature review on ICF from 2001-2009: its use, implementation and operationalisation. Disabil Rehabil 2011;33:281-09.

30. SFS 1982:763. Hälso- och sjukvårdslagen. (The health and medical services act). In Swedish. Stockholm: Socialdepartementet.

31. SFS 1993:387. Lagen om stöd och service till vissa funktionshindrade. (The act concerning support and service for persons with certain functional impairments). In Swedish. Stockholm: Socialdepartementet.

32. SFS 2001:453. Socialtjänstlagen. (The social services act). In Swedish. Stockholm: Socialdepartementet.

33. Swedish Association of Occupational Therapists. Code of ethics for occupational therapists. Nacka: Swedish Association of Occupational Therapists; 2005.

34. Nordenfelt L. Action theory, disability and ICF. Disabil Rehabil. 2003;18:1075-79. 


\section{Appendix 1: The ICF-based assessment (ICF-A): Assessment of the component environmental factors (score sheet 1)}

Client Occupational Therapist

Age Date

Gender Diagnosis

Choose an area of occupational performance (activities of daily living, work, education and leisure) and specify activity/activities.

Score each category as a facilitator or barrier for the person's occupational performance by putting an $\mathrm{X}$ in the appropriate box.

Area of occupational performance:

Activity/activities:

Assessment procedure/s (see page 4 for different data collection

methods):

Rating scale:

$\mathrm{F}=$ Facilitator

$\mathrm{B}=$ Barrier

\begin{tabular}{|l|l|l|l|}
\hline & F & B & Comments: \\
\hline $\begin{array}{l}\text { ENVIRONMENTAL FACTORS } \\
\text { CHAPTER 1 PRODUCTS AND }\end{array}$ & & & \\
TECHNOLOGY & & & \\
\hline $\begin{array}{l}\text { e110 Products or substances for } \\
\text { personal consumption }\end{array}$ & & & \\
\hline $\begin{array}{l}\text { e115 Products and technology for } \\
\text { personal use in daily living }\end{array}$ & & & \\
\hline $\begin{array}{l}\text { e120 Products and technology for } \\
\text { personal indoor and outdoor } \\
\text { mobility and transportation* }\end{array}$ & & & \\
\hline
\end{tabular}

* To be continued by all chapters in environmental factors 


\section{The ICF-based assessment (ICF-A): Assessment of the component activity and participation (score sheet 2)}

Client Occupational Therapist

Age Date

Gender Diagnosis

Choose an area of occupational performance (activities of daily living, work, education and leisure) and specify activity/activities.

Area of occupational performance:

Activity/activities:

Assessment procedure/s (see page 4 for different data collection methods):

Rate the selected activity/activities and score the component activity and participation by using the following rating scale.

Rating scale: First qualifier

$\mathrm{N}=$ No problem

(Competent performance)

$\mathrm{M}=$ Mild to moderate problem

(Questionable performance)

$\mathrm{S}=$ Severe problem

$\mathrm{V}=$ Very severe problem

(Ineffective performance)

$\mathrm{NA}=$ Not applicable

\begin{tabular}{|l|l|l|}
\hline & $\begin{array}{l}\text { First } \\
\text { qualifier }\end{array}$ & Comments: \\
\hline ACTIVITIES AND PARTICIPATION & & \\
CHAPTER 1 LEARNING AND APPLYING & & \\
KNOWLEDGE & & \\
$\begin{array}{l}\text { Purposeful sensory experiences }(d 110- \\
\text { d129) }\end{array}$ & & \\
\hline d110 Watching & & \\
\hline d115 Listening & & \\
\hline d120 Other purposeful sensing* & & \\
\hline
\end{tabular}

* To be continued by all chapters in activity and participation 


\section{Legends of tables}

Table I. Characteristics of the participants $(\mathrm{n}=11)$. Frequencies $(n)$ and percentages $(\%)$.

Table II. Chapters and categories used in the components "environmental factors" and "activity and participation" in the total number of assessments $(\mathrm{n}=99)$. Frequencies $(n)$.

Table III. Time (in minutes) required for client assessment with the ICF-based assessment $(\mathrm{n}=99)$ and rating on the score sheets for "environmental factors" and "activity and participation". Mean (range).

Table IV. The occupational therapists' perceptions on each assessment occasion about their ability to perform the ICF-based assessment. Frequencies $(n)$ and percentages (\%). 


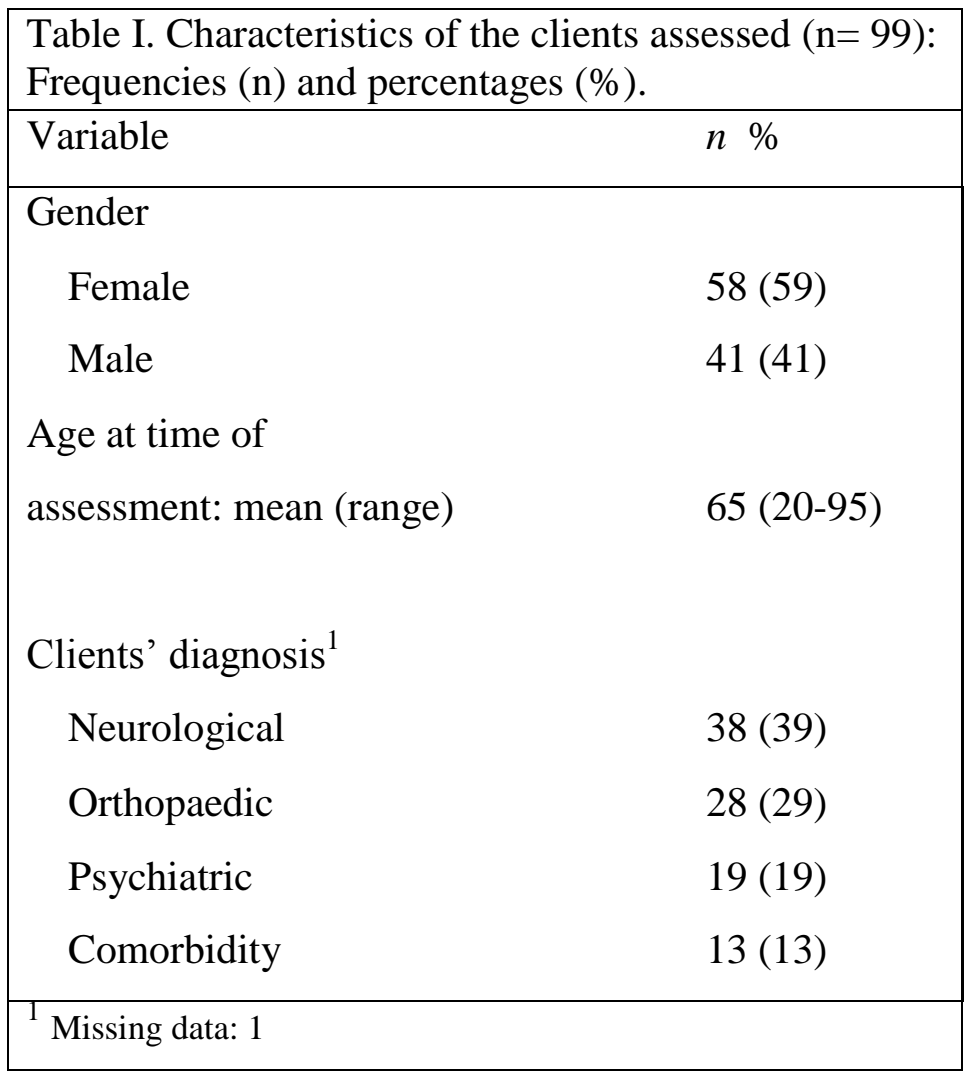




\begin{tabular}{|c|c|c|c|}
\hline Components & Chapters & Categories & Frequency (n) \\
\hline \multirow[t]{5}{*}{$\begin{array}{l}\text { Environmental } \\
\text { factors }\end{array}$} & $\begin{array}{l}\text { Chapter } 1 \text { Products and } \\
\text { technology }\end{array}$ & $\begin{array}{l}\text { e115 Products and } \\
\text { technology for personal use in } \\
\text { daily living } \\
\text { e120 Products and } \\
\text { technology for personal indoor } \\
\text { and outdoor mobility } \\
\text { and transportation }\end{array}$ & 67 \\
\hline & $\begin{array}{l}\text { Chapter } 2 \text { Natural } \\
\text { environment and human- } \\
\text { made changes to } \\
\text { environment }\end{array}$ & e240 Light & 44 \\
\hline & $\begin{array}{l}\text { Chapter } 3 \text { Support and } \\
\text { relationshins }\end{array}$ & $\begin{array}{l}\text { e310 Immediate family } \\
\text { e355 Health professionals }\end{array}$ & $\begin{array}{l}59 \\
76\end{array}$ \\
\hline & Chapter 4 Attitudes & $\begin{array}{l}\text { e410 Individual attitudes of } \\
\text { immediate family } \\
\text { e450 Individual attitudes of } \\
\text { health professionals }\end{array}$ & $\begin{array}{l}57 \\
60\end{array}$ \\
\hline & $\begin{array}{l}\text { Chapter } 5 \text { Services, } \\
\text { systems and policies }\end{array}$ & $\begin{array}{l}\text { e580 Health services, systems } \\
\text { and policies }\end{array}$ & 47 \\
\hline \multirow[t]{6}{*}{$\begin{array}{l}\text { Activity and } \\
\text { Participation }\end{array}$} & $\begin{array}{l}\text { Chapter } 1 \text { Learning and } \\
\text { applying knowledge }\end{array}$ & $\begin{array}{l}\text { d110 Watching } \\
\text { d115 Listening } \\
\text { d160 Focusing attention }\end{array}$ & $\begin{array}{l}93 \\
82 \\
81\end{array}$ \\
\hline & $\begin{array}{l}\text { Chapter } 2 \text { General tasks } \\
\text { and demands }\end{array}$ & $\begin{array}{l}\text { d210 Undertaking a single task } \\
\text { d230 Carrying out daily routine }\end{array}$ & $\begin{array}{l}83 \\
63\end{array}$ \\
\hline & Chapter 3 Communication & $\begin{array}{l}\text { d310 Communicating by } \\
\text { receiving spoken messages } \\
\text { d330 Speaking }\end{array}$ & 73 \\
\hline & Chapter 4 Mobility & $\begin{array}{l}\text { d410 Changing basic body } \\
\text { position } \\
\text { d415 Maintaining a body } \\
\text { position } \\
\text { d420 Transferring oneself }\end{array}$ & $\begin{array}{l}82 \\
90 \\
70\end{array}$ \\
\hline & Chapter 5 Self-care & d510 Washing oneself & 30 \\
\hline & Chapter 6 Domestic life & d630 Preparing meals & 9 \\
\hline
\end{tabular}




\begin{tabular}{|llc|}
\hline $\begin{array}{l}\text { Chapter 7 Interpersonal } \\
\text { interactions and } \\
\text { relationships }\end{array}$ & $\begin{array}{l}\text { d720 Complex interpersonal } \\
\text { interactions }\end{array}$ & 32 \\
$\begin{array}{l}\text { Chapter 8 Major life areas } \\
\text { and community }\end{array}$ & $\begin{array}{l}\text { d850 Remunerative } \\
\text { employment }\end{array}$ & 13 \\
$\begin{array}{l}\text { Chapter 9 Social and civic } \\
\text { life }\end{array}$ & d920 Recreation and leisure & 11 \\
\hline
\end{tabular}




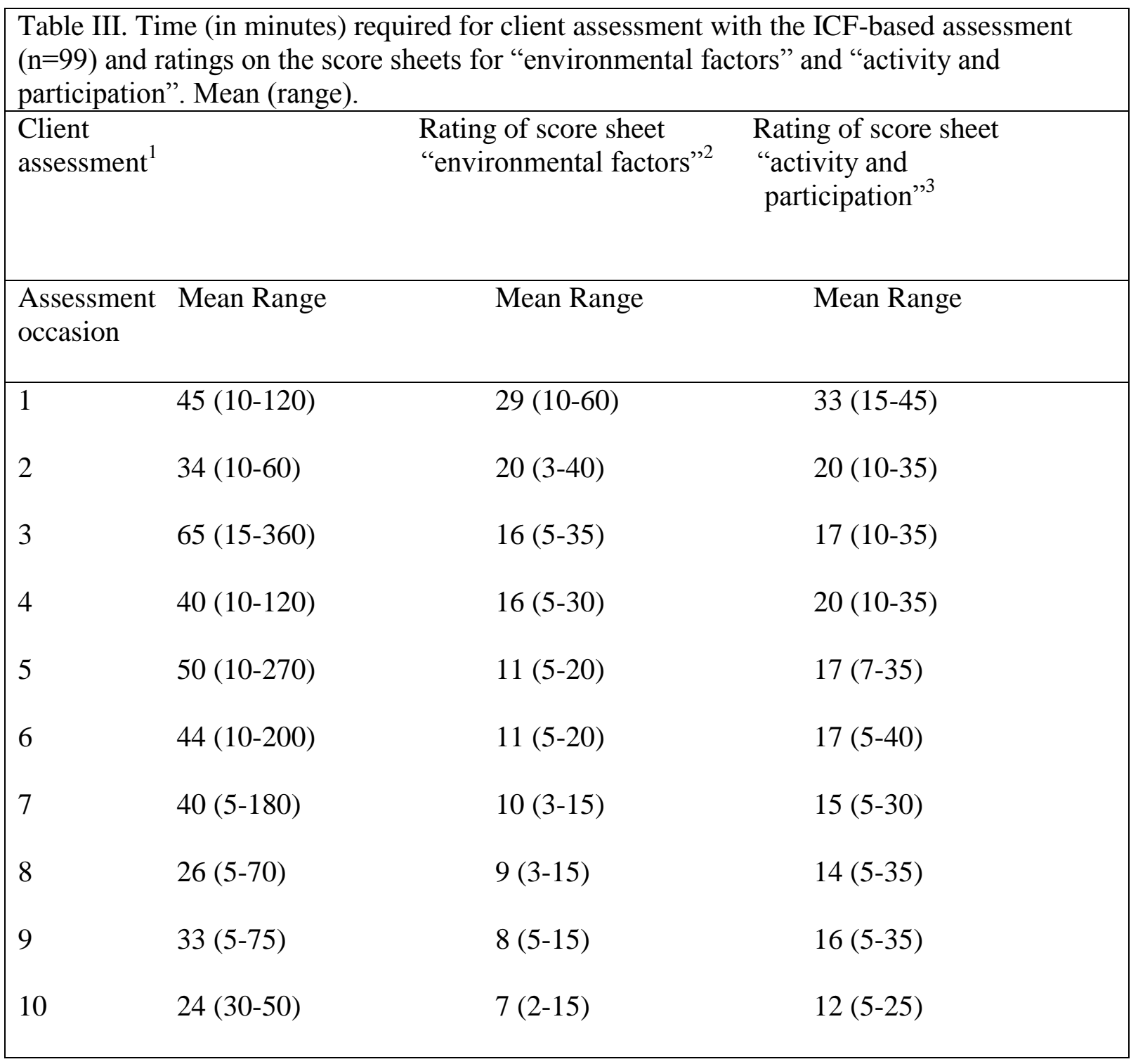

\footnotetext{
${ }^{1}$ Time required for performing the assessment

${ }^{2}$ Time required for ratings on the score sheet "environmental factors"

${ }^{3}$ Time required for ratings on the score sheet "activity and participation"
} 


\begin{tabular}{|c|c|c|c|c|}
\hline & Good & Fairly good & Not so good & Unsatisfactory \\
\hline $\begin{array}{l}\text { Assessment } \\
\text { occasion }\end{array}$ & n $\%$ & $\mathrm{n} \%$ & $\mathrm{n} \%$ & $\mathrm{n} \%$ \\
\hline 1 & $3(27)$ & $6(55)$ & $2(18)$ & $0(0)$ \\
\hline 2 & $3(27)$ & $6(55)$ & $2(18)$ & $0(0)$ \\
\hline 3 & $3(27)$ & $8(73)$ & $0(0)$ & $0(0)$ \\
\hline 4 & $6(55)$ & $5(46)$ & $0(0)$ & $0(0)$ \\
\hline 5 & $5(50)$ & $4(40)$ & $1(10)$ & $0(0)$ \\
\hline 6 & $6(60)$ & $4(40)$ & $0(0)$ & $0(0)$ \\
\hline 7 & $5(50)$ & $5(50)$ & $0(0)$ & $0(0)$ \\
\hline 8 & $6(67)$ & $3(33)$ & $0(0)$ & $0(0)$ \\
\hline 9 & $5(63)$ & $3(37)$ & $0(0)$ & $0(0)$ \\
\hline 10 & $5(63)$ & $3(37)$ & $0(0)$ & $0(0)$ \\
\hline
\end{tabular}

